Please send trade news information and

illustrations to Arveen Bajaj at the BDJ, Nature

Publishing Group, The Macmillan Building,

4-6 Crinan Street, London N1 9XW.

Trade news is provided as a service to readers

using text and images from the manufacturer,

supplier or distributor and does not imply

endorsement by the $B D J$. Normal and prudent

research should be exercised before purchase or

use of any product mentioned.

\section{Precision handling}

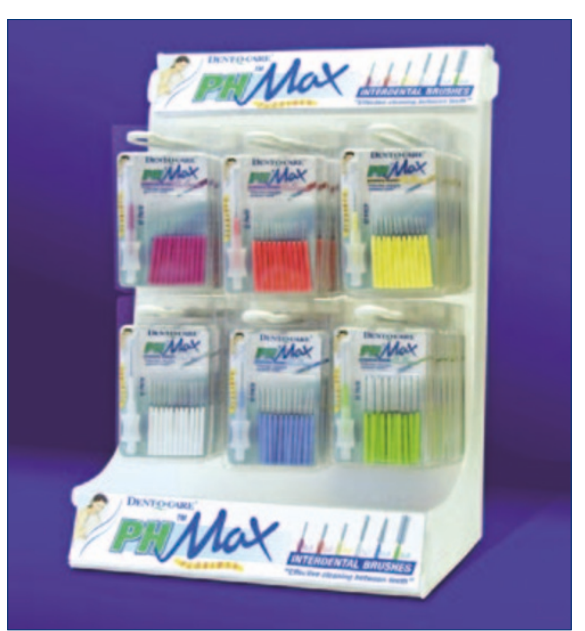

Dent-0-Care has launched its new flexible PH Max range. PH Max means Precision Handling with Maximum benefit and each pack has 12 brushes, a grip holder and an extension handle that doubles as a protective cap.

Unlike other hand held designs, there is no need to reshape the brush before using. Flexing the handle with the index finger tilts the brush head to achieve the best angle for cleaning between teeth.

The range of six sizes with plastic coated cores $(0.4-0.9 \mathrm{~mm})$ is also ideal for bridges, braces and implants. A pack of $\mathrm{PH}$ Max is $£ 1.89$ with a suggested patient price of £3.49.

Patient test packs containing one of each size plus attachments are 80p. The company is currently offering the PH Max unit worth £15 plus one dozen patient test packs free, when you order 72 packs of PH Max from Dent-0-Care, until 30 June.

Reader response number 52

\section{Spa-like comfort}

CollarDam is a new patient protection dental bib which provides patients with maximum protection and spa-like comfort during long and intricate procedures. The bibs eliminate cold draughts around patients' necks as well as absorb-

\section{Non-injectable local anaesthetic}

Oraqix, Dentsply's non-injectable dental local anaesthetic was the subject of a recent competition won by Dr Shaminder Bansal (pictured) at the BDTA London Dental Showcase. He was presented with a cheque for $£ 5,000$.

Oraqix is indicated in adults for localised anaesthesia in periodontal pockets for diagnostic and treatment procedures such as probing, scaling and/or root planing. Its patented thermosetting property keeps it in place for effective absorption, anaesthesia occurs within 30

\section{A natural alternative}

OralClens Natural from Oraldent is a new range of toothpaste and mouthwash, the active ingredients of which are 100\% natural. As a natural alternative to conventional, synthetic products they are kinder and gentler on the mouth and gums.

OralClens Natural toothpaste and mouthwash is a unique oral cleansing solution that contains a powerful anti-bacterial extracted from the pith of oranges, called Citroxx. The patented blend of non-toxic bioflavinoids and fruit acids contains no alcohol, no SLS, no synthetic anti-bacterials, and no synthetic sweeteners or flavourings. In addition the Citroxx natural anti-bacterial will kill the germs that can cause bad breath and protect against cavities.

Suitable for both adults and children, OralClens Natural will leave your mouth feeling fresher and cleaner and is avail-

ing moisture and spilt or excess fluids.

The bibs are individually wrapped, absorbent and disposable, ensuring all cross infection guidelines are met. A high-tech design features crystals and fibre which change colour when wet to alert clinicians when a change of bib is due, ensuring the patient's levels of

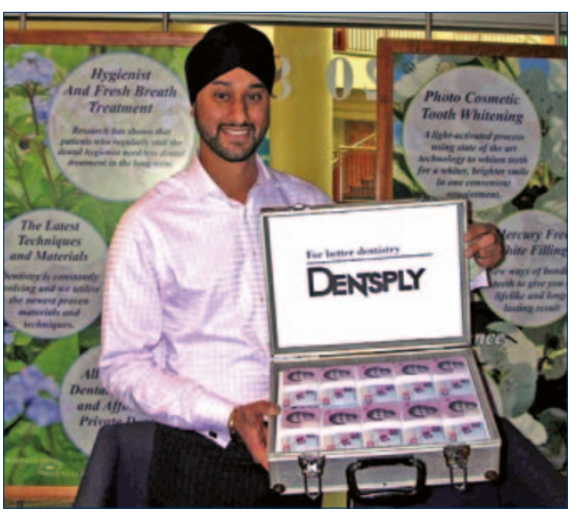

seconds and there is no post-procedural numbness.

Reader response number 50

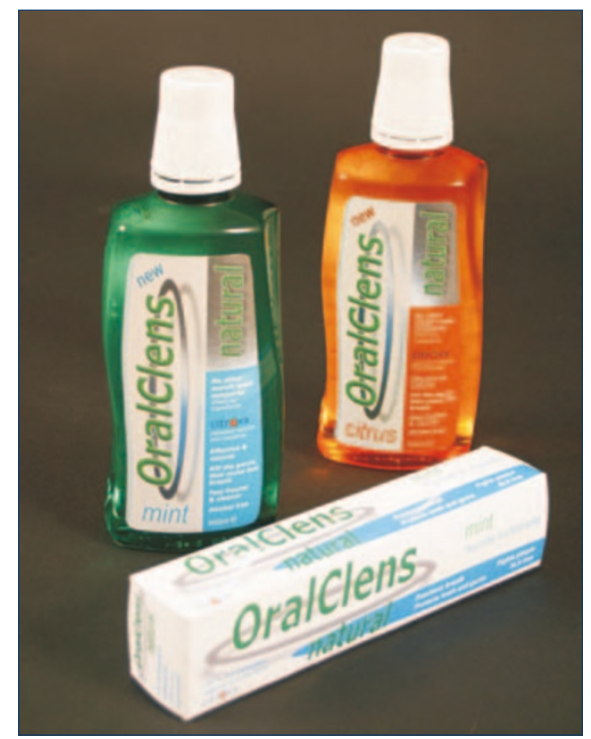

able in fresh mint flavour or tasty citrus. For your free sample please email Oraldent at sales@oraldent.co.uk.

Reader response number 51

protection and comfort are maintained.

Originally designed by dentists and inspired by the increasingly competitive nature of modern dental practice, the dentists who devised the CollarDam concept were determined that their patients should be made as comfortable as possible.

Reader response number 53 


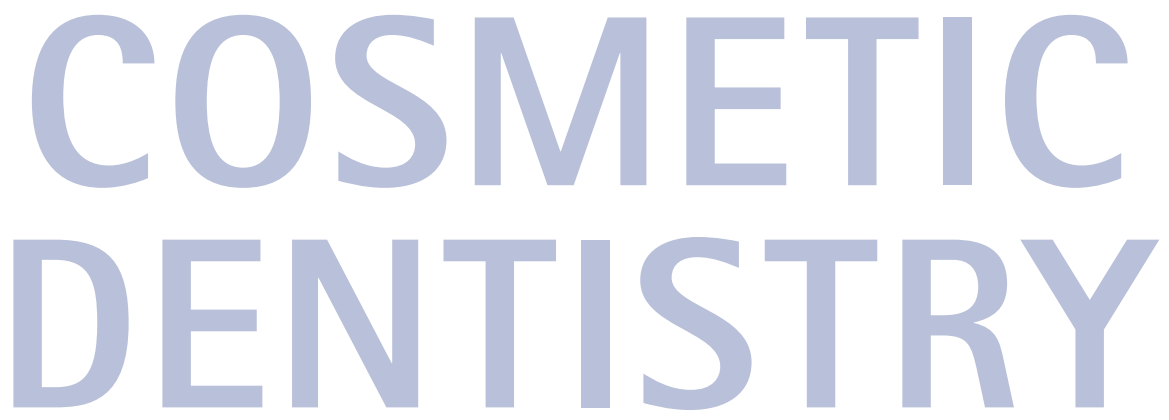

\section{Simple bleaching}

\section{process}

Dentsply's Illuminé system has no need for light or heat activation making the whole bleaching process simpler, quicker and more cost-effective. The system itself is available as 'In Office' or 'At Home' treatments, or a mixture of the two. After mixing, Illuminé Office yields 15\% hydrogen peroxide that begins to set to a rubbery semi-solid, eliminating the need for gingival isolation.

After the treatment is administered, the patient can sit comfortably in the waiting room, freeing up the dental chair for other patients. Illuminé Office may also be used as a 'kick-start' to a three-day Illuminé Home (10\% or 15\% carbamide peroxide) treatment, as a post-whitening touch up, or as a stand-alone treatment from one to three 30-minute visits, depending on results. Dentsply also has a range of free patient marketing literature to help support your business.

Reader response number 56

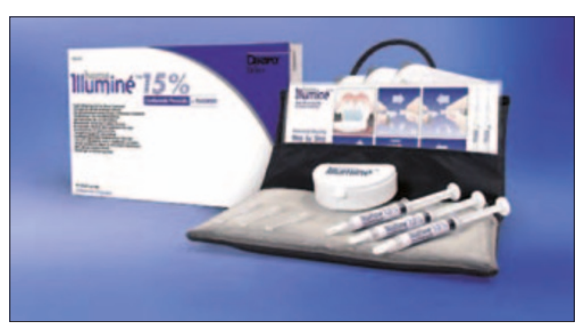

\section{Fast and effective}

The new WIS Light II from DMDS gives you the choice of fast and effective whitening with either LED or Pulsation Technology from one simple to use portable, lightweight unit. It is a combined unit that allows you to use the same system whichever option you choose to use.

The LED provides high concentration

\section{Ergonomic seating range}

With an emphasis put on the health of the seated operator in the workplace, British medical equipment manufacturer, Beautelle has an ergonomic seating range that can help to reduce work related upper limb disorders, decrease pain and fatigue associated with muscular tension, reduce lower back pain, relieve posture problems and improve blood circulation.

The Saddle Stool allows the spine to maintain its physiological curves and

\section{Long lasting restoration}

Applied in a single step, Diamond Snappy from Kemdent has been specially designed for fast, long lasting restorations in deciduous teeth but now Kemdent also recommend Diamond Snappy for temporary fillings in adult teeth. It is quick, easy to use and is resistant to saliva as soon as the cavity is filled.

The product has no unpleasant after taste and no primer or bonding agent is required. Snappy contains no additional pigments and is available in a natural white shade. It sets in less than three minutes from start of mix at $23^{\circ} \mathrm{C}$. In

and quick whitening while the Pulsation option is used for fast custom tray whitening. Both provide swift, safe and effective long-term dual arch whitening in five to ten minutes.

It is supplied complete with two pairs of safety glasses, four cheek retractors, whitening head, pulsation head, power adapter and complete instruction manual. It is completely portable as it is bat-

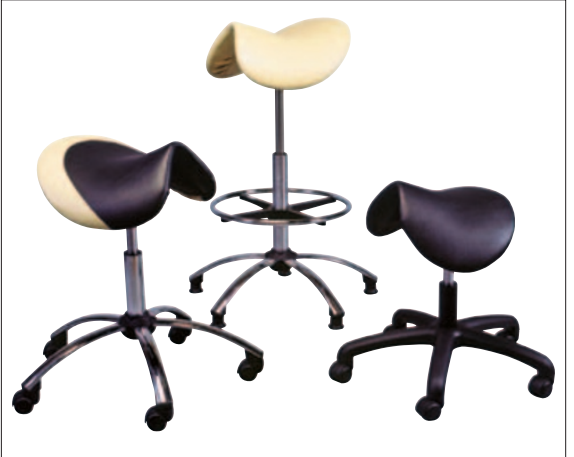

provides correct posture and support. Beautelle’s Prices start at $£ 100$ plus vat. Reader response number 54

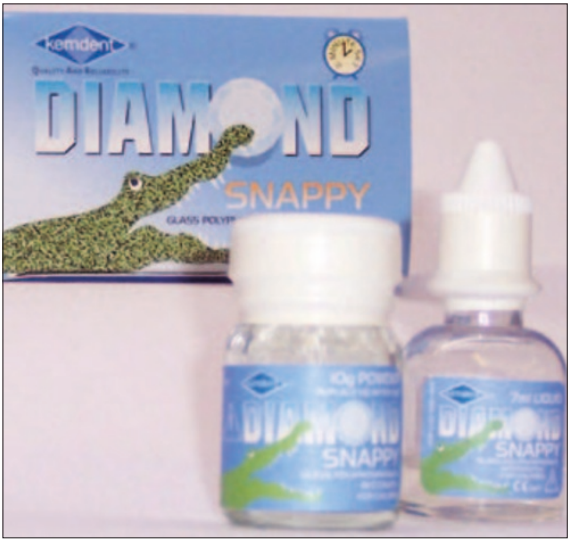

April, if you buy one pack of Diamond Snappy you get another pack free.

Reader response number $\mathbf{5 5}$ 


\section{One stop technology}

Cerec restorations (inlays, onlays, partial crowns, crowns and veneers) are completed in a single visit eliminating the need for conventional impressions and laboratory services. The ceramics used enable the production of restorations that are the closest yet to natural tooth substance allowing you to meet all requirements fully in terms of aesthetics, fracture strength, abrasion characteristics and function.

Reader response number 58

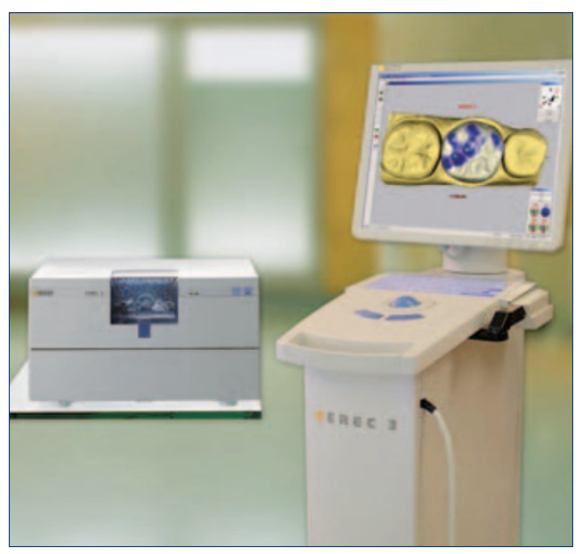

\section{Metal-free dental restorations}

Shofu's two porcelain systems have been developed in response to patient demand for aesthetic, metal-free dental restorations. Vintage ZR is ideal for all popular zirconium oxide crown and bridge framework systems. It has colour harmonisation with natural teeth and a fine, homogeneous particle structure.

The Vintage AL veneer porcelain sys-

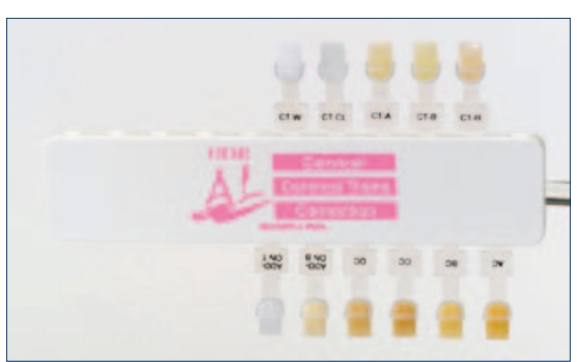

tem is specially developed to optimise aluminium oxide frameworks. It has good shade match with natural teeth, metal-bond or all-porcelain restorations with easy handling.

Both materials are designed to combine an easy working technique with good physical characteristics, plus natural aesthetics even with thin layers of material. Special liner materials enable technicians to control the opacity of the framework, so they can count on rapid and efficient layer build-ups plus complete colour accuracy.

A lifelike appearance is assured through optimum light transmission and colour co-ordination with the Vita* Classical colour system.

Reader response number 59

\section{Unique particle structure}

Due to the shade adaptation of GC's Gradia Direct to the surrounding tooth structure, the material will provide you with aesthetic results because of its unique particle structure and light reflectiveness.

When dealing with more demanding and complex cases a combination of different shades enables unlimited aesthetic results. GC Gradia Direct offers you the complete assortment from bleach white to dark translucent to outside special shades.

Radiopaque GC Gradia Direct Posterior combines aesthetics with mechanical properties by means of high fracture toughness to resist occlusal stress, high wear resistance and low wear on opposing dentition.

GC have developed a new shade guide that takes into account the chroma, hue and value of each composite shade whether you have opted for a singleshade or if you are extensively restoring a tooth and require multiple shades. This shade guide incorporates two special shades, which are placed underneath or on top of a standard shade to further enhance your restoration.

Reader response number 60

Enlighten offers all customers its range of free marketing materials with the Evolution Whitening System. The pack includes brochures, postcards, posters, window stickers and an image CD.

Enlighten also offers a free studio design service for adverts, gift vouchers and promotions.

Reader response number 61 